\title{
FENOMENOLOGIA E EDUCAÇÃO: AS BASES HUSSERLIANAS E SUAS IMPLICAÇÕES METODOLÓGICAS
}

\author{
Victor Leandro da Silva ${ }^{1}$ \\ Thaise Silva Ferro Gomes ${ }^{2}$
}

\begin{abstract}
Resumo:
A fenomenologia tem se destacado como um dos mais profícuos métodos aplicados na pesquisa em educação. No entanto, esse avanço também implicou uma redução de seu alcance teórico, circunscrito a um conjunto de orientações que muitas vezes não se coadunam a suas linhas fundamentais. Partindo dessa problemática, o presente texto visa retomar os princípios epistemológicos da fenomenologia de Edmund Husserl, em especial no que tange à relação sujeito-mundo, para, com base em suas proposições, articulálas à discussão na pesquisa educativa envidada pelo filósofo Maurice Merleau-Ponty. Como resultado, o que se pretendeu foi elucidar em que arcabouço as ciências da educação precisam estar orientadas para servirem-se do pensar fenomenológico, no que é imprescindível fazer um uso adequado de sua estrutura conceitual.
\end{abstract}

Palavras-chave: Fenomenologia. Método. Essência. Intersubjetividade. Pesquisa educativa.

\section{PHENOMENOLOGY AND EDUCATION: THE HUSSERLIAN BASES AND THEIR METHODOLOGICAL IMPLICATIONS}

\begin{abstract}
:
Phenomenology has stood out as one of the most fruitful methods applied in educational research. However, this advance also implied a reduction in its theoretical scope, limited to a set of guidelines that often diverge with its fundamentals. Based on this problem, the present text aims to return to the epistemological principles of Edmund Husserl's phenomenology, especially concerning the subject's relationship with the world. Based on these proposals, this essay aims to articulate them to the discussion in the educational research undertaken by the philosopher Maurice Merleau-Ponty. As a result, it was intended to elucidate by which framework the educational sciences need to be oriented to use phenomenological thinking, which demands the appropriate use of its conceptual structure.
\end{abstract}

Keywords: Phenomenology. Method. Essence. Intersubjectivity. Educational research.

\section{Introdução}

Dentre os métodos possíveis para a pesquisa em educação, a fenomenologia tem se destacado como uma das mais contempladas no âmbito da chamada pesquisa qualitativa. Desse modo, o pensar fenomenológico constituiu-se numa das principais vertentes epistemológicas exploradas na abordagem dos objetos educativos.

No entanto, em vista de sua propagação, houve também uma conversão dos princípios fenomenológicos em fórmulas fixas e diretivas, a fim de facilitar a transmissão

1 Licenciado em Filosofia pela UFAM. Doutor em Sociedade e Cultura na Amazônia pela Universidade Federal do Amazonas. Professor Adjunto da Universidade do Estado do Amazonas. Professor permanente do Programa de Pós-graduação em Educação - UEA. E-mail: viktorleandro@ hotmail.com. 2 Licenciada em Letras pela UFPI. Mestra em Letras pela Universidade Federal do Amazonas. Professora da Secretaria Estadual de Educação - Amazonas. E-mail: thaiseferrogomes@ hotmail.com. 
Victor Leandro da Silva/ Thaise Silva Ferro Gomes

de seu ensino. Como resultado, sua complexidade inerente acabou transformando-se numa série de prescrições que culminaram numa disciplina reduzida, que não vai a fundo na abordagem das questões que se propõe a esclarecer, o que se reflete sobremaneira nos resultados investigativos.

Assim, para que se possa situar novamente o lugar da fenomenologia enquanto método necessário à pesquisa educativa, é mister retomar os conceitos atinentes as suas raízes filosóficas, bem como articular, de maneira assertiva, o mais profundo rigor fenomenológico com as bases das ciências da educação.

\section{Edmund Husserl: o sujeito e a essência}

A abordagem fenomenológica de Edmund Husserl se arvora mediante os problemas suscitados por aquilo que ele convencionou chamar de crise das ciências europeias, ou do modelo positiva, que, embora tivesse trazido progressos evidentes ao conhecimento científico, começava a dar sinais de insuficiência no que dizia respeito ao seu alcance investigativo, em especial no âmbito dos acontecimentos relativos à experiência humana, cujos caracteres escapavam aos esquemas trazidos pelo paradigma indutivo. Em vista disso, ele se propõe a pensar um novo modelo epistemológico que colocasse o homem novamente no centro de sua atenção.

Diante dessa conjuntura, Husserl irá considerar que os princípios fenomenológicos por ele elaborados seriam capazes de fazer a filosofia saltar de seus impasses metafísicos para uma doutrina das essências, articulada com o mundo e pautada em critérios significativos de objetividade, no que seu vínculo à ciência poderia ser efetivamente definido:

Se abstrairmos das metas metafísicas da crítica do conhecimento, atendo-nos apenas à sua tarefa de elucidar a essência do conhecimento e da objectalidade cognitiva, ela é então fenomenologia do conhecimento e da objectalidade cognitiva e constitui o fragmento primeiro e básico da fenomenologia em geral (HUSSERL, 2015, p. 44).

Tais proposições apontam para uma designação diretiva da fenomenologia, a qual o filósofo esclarece com precisão:

'Fenomenologia' - designa uma ciência, uma conexão de disciplinas científicas; mas, ao mesmo tempo e acima de tudo, 'fenomenologia' designa

\begin{tabular}{|l|c|c|c|c|}
\hline Govista Dialectus & Ano 9 & n. 19 & Agosto-Dezembro 2020 & p. 13-24 \\
\hline
\end{tabular}


um método e uma atitude intelectual: a atitude intelectual especificamente filosófica, o método especificamente filosófico (p. 44).

Com isso, está-se diante de um método que, ao mesmo tempo em que se articula a todas as ciências, apresentando-se como o elo entre elas, determina-se também como sendo uma casa de força da filosofia, assegurando suas formas próprias e significativas de atuação no mundo empírico.

Importante notar aqui a postura crítica de Husserl no que diz respeito às preconizações feitas em torno do método positivista, pautado na observação e experimentação, e que deveria, conforme progredisse, assumir a totalidade dos processos relativos ao conhecimento. Para ele, a hipótese de que a filosofia deveria ser, num certo sentido ou literalmente, subsumida pelas ciências, não pode ser efetivada, sob pena de privar-se de sua mais aguda contribuição. Desse modo, é que irá despontar, no seio de sua teoria, uma defesa firme dos critérios filosóficos classicamente instituídos, porém numa nova base de considerações. Portanto, para Husserl,

Hoje, deve ainda designar-se como predominante a opinião de que a filosofia e, mais concretamente, a doutrina suprema do ser e da ciência - pode estar não só relacionada com todas as restantes ciências, mas também fundada nos seus resultados, / da mesma maneira que as ciências se baseiam umas nas outras e os resultados de umas podem actuar como premissas das outras. (HUSSERL, 2015 , p. 45).

Surgem daí inicialmente as Meditações cartesianas, em que ele fala da necessidade de uma redução fenomenológica, ou seja, de uma abstração total que chega até o isolamento do eu individual que "inibe o valor existencial do mundo objetivo" (HUSSERL, 2001, p. 43) para em seguida, partindo do sujeito, encontrar os fundamentos de toda e qualquer relação entre homem e meio. Nesse caminho, o que finda por ser valorizado não é um suposto objeto exterior, mas sim a maneira como este chega ao indivíduo como forma de experiência. É, portanto, uma forma de pensamento amplamente centrada no sujeito, e que põe em questão, não no sentido da existência, mas no da forma de apreensão epistemológica, a realidade daquilo que lhe é externo.

Por conseguinte, na abordagem fenomenológica, existe uma preocupação profunda em voltar-se para a exploração dos traços mais intrínsecos da ligação do sujeito com o mundo. Pelo método da fenomenologia, afirma Husserl, o indivíduo é conduzido, através de sua redução fenomenológica, até os limites essenciais de sua experiência dos fenômenos, desvelando a “estrutura do 'eidos' universal do ego transcendental, que,

\begin{tabular}{|l|c|c|c|c|}
\hline Govista Dialectus & Ano 9 & n. 19 & Agosto-Dezembro 2020 & p. $13-24$ \\
\hline
\end{tabular}


Victor Leandro da Silva/ Thaise Silva Ferro Gomes

abrange todas as variantes possíveis do meu ego empírico e, portanto, esse próprio ego" (HUSSERL, 2001, p. 88). Desse modo, o eu revela-se em seus traços universalizantes pela maneira como seu relaciona com os fenômenos.

Por outro lado, a fenomenologia também defende a independência de cada experiência, que sempre aparece com um caráter de novidade, posto estar ligada a uma consciência que o percebe no instante de sua experimentação:

Portanto, a toda consciência que é consciência de alguma coisa pertence essa propriedade essencial: não somente ela pode, de maneira geral, transformar em modos de consciência sempre novos, permanecendo consciência de um objeto idêntico (HUSSERL, 2001, p. 63).

Logo, mesmo diante de objetos conhecidos, a apresentação destes à consciência nunca é a mesma, posto que estes se colocam agora de um modo ainda desconhecido para a consciência do indivíduo, tendo de ser percebidos em sua aparição presente. Assim, o olhar fenomenológico é sempre para o novo.

Nesse conjunto de argumentações, um problema emerge como pertinente. De que maneira é possível superar o solipsismo que decorre da atitude fenomenológica? Ora, se o conhecimento está circunscrito ao sujeito, como é possível que nos tornemos capazes de comunica-lo e de socializa-lo entre nós? Eis uma pergunta da qual Husserl não se esquiva e busca responder de forma bastante rigorosa.

Para resolver a questão, ele recorre à ideia de estruturas universais, que constituem a forma de organização do sujeito. É através delas que somos capazes de nos situarmos no mundo, bem como de estabelecer uma articulação entre nossas constatações particulares e proposições de caráter geral:

Notadamente as formas nas quais existo somente como ego, e somente nas quais - tomando-se isso numa universalidade da essência - posso existir assim. É preciso contar entre elas (entre outras) a maneira de existir sob a forma de certa vida universal em geral, sob a forma de constituição constante por si mesma e seus próprios estados como temporais no interior de um templo universal (2001, p. 117).

Quando imergimos na redução fenomenológica, também perscrutamos as estruturas de nossa compreensão, as quais, por serem universais, revelam traços de uma experiência comum a todos os indivíduos. Desse modo, é que podemos falar de um conhecimento que, ao mesmo tempo em que se gera em nós, é capaz de migrar para os

\begin{tabular}{|l|c|c|c|c|}
\hline Govista Dialectus & Ano 9 & n. 19 & Agosto - Dezembro 2020 & p. $13-24$ \\
\hline
\end{tabular}


Victor Leandro da Silva/ Thaise Silva Ferro Gomes

demais sujeitos e para toda a humanidade, tornando transmissível a vivência compartilhada de mundo:

\begin{abstract}
A intersubjetividade transcendental possui, graças a essa colocação em comum, uma esfera intersubjetiva de vinculação, em que ela constitui de maneira intersubjetiva o mundo objetivo; ela é dessa forma, na qualidade de um 'nós' transcendental, sujeito para esse mundo e também para o mundo dos homens, forma sob a qual esse sujeito se realiza ele próprio como objeto. (HUSSERL, 2001, p. 121).
\end{abstract}

Se nos colocamos do lado de nossa subjetividade, inevitavelmente nos pomos também no plano intersubjetivo, e, nele, revela-se nossa manifestação do mundo, a qual, por estar ligado ao que se capturou da realidade exterior, evidencia-se como a forma mais concreta de nossa experimentação objetificada, obtendo-se, com isso, uma construção igualmente rigorosa no sentido objetivo e também da realidade de nossas estruturas universais.

Importante observar ainda que Husserl considera, como bem ficou salientado em outro dos seus textos (2006), que nossa capturação do mundo objetivo é pautada por limitações, as quais fazem com que o observado externamente obtenha um caráter inevitavelmente parcial:

\begin{abstract}
Também um vivido jamais é completamente percebido, ele não é adequadamente apreensível em sua unidade plena. Ele é, por essência, um fluxo, que, se dirigirmos o olhar reflexivo para ele, podemos acompanhar desde o momento presente, mas cujos trechos percorridos estão perdidos na percepção. Temos uma consciência do que acaba imediatamente de decorrer somente na forma da retenção, na forma, por exemplo, da rememoração retroativa. (p. 105).
\end{abstract}

Se os dados obtidos no mundo são sempre parciais e restritos, deixando clara que estes a forma de percepção, e se na intersubjetividade se revela a estrutura, que é dada na maneira de uma experiência do mundo, então a sensibilidade constituída no sujeito pode ocupar, no processo epistêmico, uma posição bastante expressiva. Apontando para esse caminho, é que Husserl assevera que "à tese do mundo, que é uma tese 'contingente', contrapõe-se, portanto, a tese de meu eu puro e da vida do eu, que é uma tese 'necessária' (2006, p. 109). Portanto, o que se torna universalmente válido em cada experiência são justamente os elementos próprios do eu, configurados no momento de sua apreensão empírica:

\begin{tabular}{|l|c|c|c|c|}
\hline Govista Dialectus & Ano 9 & n. 19 & Agosto - Dezembro 2020 & p. $13-24$ \\
\hline
\end{tabular}


Assim, pois, está de todas as maneiras claro que tudo aquilo que está para mim aí no mundo-de-coisas, é por princípio somente realidade presuntiva; mas está claro, ao contrário, que eu mesmo, para quem aquilo está aí (por exclusão daquilo que é por mim atribuído ao mundo-de-coisas) mais exatamente, que minha atualidade de vivido é efetividade absoluta, dada por uma posição incondicionada, pura e simplesmente insuprimível (p.109).

Dessa maneira, seguindo pelo percurso husserliano, o que a fenomenologia revela são sobretudo as formas universais da experiência humana. Logo, quando estamos diante de um objeto, obviamente temos os dados sensoriais deste. Porém, o que se mostra ali em sua completude é não o objeto, posto que este é registrado nos sentidos dentro de uma parcialidade, e sim a experiência do ver, a qual, por suas características estruturantes, articula-se igualmente nos indivíduos, tornando compreensível a maneira por que o mundo é por nós assimilado.

As observações de Husserl, dirigindo o olhar para uma nova maneira de abordar os objetos existentes na realidade, findam por produzir fortes implicações metodológicas, gerando uma série de desdobramentos investigativos em diversos ramos e temas de investigação. É isso, por exemplo, que pondera o filósofo Martin Heidegger, discípulo de Husserl, para quem a fenomenologia ordenava o método adequado para suas investidas acerca do estudo do ser:

\begin{abstract}
Com a questão diretriz sobre o sentido de ser, a investigação acha-se dentro da questão fundamental da fenomenologia em geral. O modo de tratar esta questão é fenomenológica. Isso, porém, não significa que o tratado prescreva "um ponto de vista" ou uma "corrente". Pois, enquanto se compreender a si mesma, a fenomenologia não é e não pode ser uma coisa nem outra. A expressão 'fenomenologia' significa, antes de tudo, um conceito de método. Não caracteriza a qualidade real dos objetos da investigação filosófica, o quê dos objetos, mas o seu modo, o como dos objetos. Quanto mais autenticamente opera um conceito de método e quanto mais abrangentemente determina o movimento dos princípios de uma ciência, tanto maior a originariedade em que ele se radica numa discussão com as coisas elas mesmas e tanto mais se afastará do que chamamos de artifício técnico, tão numeroso nas disciplinas teóricas (HEIDEGGER, 2015, p. 66).
\end{abstract}

Tal vocação para constituir-se enquanto método irá aparecer não somente nos meandros da filosofia, como também nas diversas áreas de conhecimento, com especial atenção naquelas que tratam dos acontecimentos relativos ao ser humano. Nestas, o componente fenomenológico parece ingressar com um vigor muito maior em vista das menores resistências, o que se deve em muito à ênfase dada por ela aos traços mais intrínsecos da experiência humana.

\begin{tabular}{|l|c|c|c|c|}
\hline Gevista Dialectus & Ano 9 & n. 19 & Agosto-Dezembro 2020 & p. 13-24 \\
\hline
\end{tabular}


Os eventos relativos à educação, como era de se imaginar, também são sensíveis às proposições fenomenológicas. Estas irão aparecer, de maneira frequente nos estudos realizados, bastante próximas de objetos que são fundamentais na pesquisa em educação, principalmente quando se trata de discutir os processos mais internos da aprendizagem.

No entanto, esse elo tão facilmente identificável esconde uma série de problemas que dizem respeito à visada fenomenológica na abordagem em educação, de modo a criar um falso automatismo na vinculação epistemológica entre o método e o campo de pesquisa, o que resulta numa precariedade quanto à aproximação desses diversos objetos e suas especificidades.

Assim, para compreender o real lugar da fenomenologia dentro da pesquisa em educação, faz-se necessário articular de que maneira os princípios fixados fundamentalmente por Husserl se adequam ao mundo trazido pelos fenômenos educativos, procedendo, dessa maneira, a um exame rigoroso de suas possibilidades de ligação.

\section{A visada fenomenológica na pesquisa educativa}

Conforme foi avançando em suas aplicações, o método fenomenológico foi encontrando novas perspectivas de investigação, de acordo com a área em que foi aproveitado. Obviamente, isso levou ao surgimento de importantes acréscimos e reinterpretações, que modificaram, em parcelas maiores ou menores, as ideias trazidas pelos seus principais precursores.

$\mathrm{Na}$ educação, com uma trajetória bastante expressiva, houve uma significativa gama de aproveitamentos dos preceitos fenomenológicos. Contudo, se estudos ligados, por exemplo, ao interacionismo de Piaget, tiveram notável avanço, houve, no plano prescritivo, um sensível decréscimo no que diz respeito a sua propagação, resultando em acepções simplórias e redutoras, que, não obstante os seus aspectos limitadores, tomaram conta dos manuais de pesquisa, proliferando-se de maneira quase total no meio destes, resultando em visões pouco producentes. A título de exemplo, vejamos como é explicitada a relação entre fenomenologia e pesquisa educativa no trecho a seguir, retirado de um bastante difundido livro de metodologia:

$21 \mathrm{O}$ enfoque fenomenológico, com bases antropológicas, tem privilegiado, antes que o lar, a escola. Nela, exaltaram os estudos na sala de aula. Uma

\begin{tabular}{|l|c|c|c|c|}
\hline Govista Dialectus & Ano 9 & n. 19 & Agosto-Dezembro 2020 & p. 13-24 \\
\hline
\end{tabular}


tendência, o interacionismo, tendo como meio a sala de aula, alcançou notável desenvolvimento. Segundo nosso ponto de vista, a experiência dos antropólogos e de suas pesquisas em tribos fixas, com suas culturas e seus valores, inspirou aos fenomenólogos à busca de "modelos semelhantes" que foram encontrados nos grupos regulares e definidos de alunos.

22. Os estudos de sala de aula, separados de todos os elementos históricos e sociais amplos, são uma amostra muito clara do isolamento do fenômeno em foco.

23. Por outro lado, a interpretação dos fenômenos que se apresentam numa sala de aula oferece a possibilidade de esclarecer alguns elementos culturais, como os valores, que caracterizam o mundo vivido dos sujeitos. (TRIVIÑOS, 1987, p. 48).

O que se tem aqui é uma posição fincada exclusivamente no mundo dos sujeitos, colocando a fenomenologia do lado de um subjetivismo ingênuo, o que contradiz em muito aquilo que Husserl previu em boa parte dos seus textos. O pensamento fenomenológico, longe de se constituir em meros juízos individuais depurados, aponta para uma compreensão da realidade que parte das estruturas universais humanas para revelar o que de mais essencial há naquilo que está em volta destas. Logo, propostas desse tipo, que não consideram o que de mais profundo foi revelado pela tradição fenomenológica acerca da relação sujeito-objeto, nada mais fazem do que esterilizar sensivelmente o seu campo de aplicabilidade.

Os exemplos poderiam se seguir de forma numerosa, porém, não é o objetivo tratar da fenomenologia dos manuais, e sim tentar definir o pensamento fenomenológico e suas repercussões educativas. Para tanto, é válido observar de perto os estudiosos que envidaram suas linhas de pensamento dentro desse conjunto de problematizações, e que apontaram caminhos para se conduzir de maneira prolífica o pensar fenomenológico na educação.

Seguindo por essa linha, é que, mais até do que em Piaget, o pensamento educacional elaborado pelo filósofo Maurice Marleau-Ponty, representa um importante caminho para a interpretação dos achados fenomenológicos e de seus aproveitamentos pedagógicos, particularmente no âmbito da pesquisa.

É patente a vinculação de Merleau-Ponty ao pensamento fenomenológico, bem como os pontos em que ele amplia as concepções trazidas por Edmundo Husserl, expressas sobretudo em sua obra mais rigorosa, Fenomenologia da Percepção (1999), em que o corpo é analisado como um item integrante do processo de captação do mundo, e sem o qual desdobrar-se do pensamento junto aos eventos é impossível. Assim, é nesse

\begin{tabular}{|l|c|c|c|c|}
\hline Q Povista Dialectus & Ano 9 & n. 19 & Agosto - Dezembro 2020 & p. $13-24$ \\
\hline
\end{tabular}


eixo de diálogo e ampliação dos achados husserlianos que a filosofia do pensador francês se orienta, trazendo consequências que irão se estender da análise estética à psicologia.

No que diz respeito à pedagogia, suas proposições, fortemente ligadas à psicologia da criança, mas com repercussões na pesquisa educativa, resultaram em importantes apontamentos metodológicos, os quais, sob a égide da fenomenologia, direcionam-se para um novo conjunto de pressupostos investigativos, bem distantes das estereotipações envidadas comumente:

\begin{abstract}
A psicologia não é simples anotação de tudo o que a criança diz e faz: aí só se encontram traços de uma dinâmica do desenvolvimento resultante da constelação familiar, do meio social. O fato histórico nada é, e só a significação é válida. O fato qualitativo é original e reconstruído (MERLEAU-PONTY, 2006, p. 471).
\end{abstract}

Aqui, já é possível perceber o quão equivocadas sãos as posições que consideram que o trabalho fenomenológico consiste fundamentalmente em um registro descritivo, quando na verdade sua exigência vai muito além desses termos, trazendo para o centro da investigação a necessidade de observar o objeto em toda sua dinâmica constitutiva. Nesse momento, é que aparece o cerne da atividade fenomenológica, que está sobretudo na possibilidade de elaborar uma descrição muito mais profunda, que vá à essência do fenômeno observado, ao mesmo tempo em que lhe conferirá um significado que permita apreendê-la em seu devir, bem como em sua universalidade, pois, como assinala Merleau-Ponty, "esse saber qualitativo não é subjetivo, é intersubjetivo: descreve o que é observável para todos" (2006, p. 6).

Dentro desse processo, a figura do pesquisador aparece como um ser integrante da investigação, uma vez que é no seu horizonte que aparecem os elementos a serem observados. "Somos para nós mesmos o nosso próprio fundo. Para que o conhecimento progrida, para que haja conhecimento científico do 'outro', o que era fundo precisa tornar-se figura” (MERLEAU-PONTY, 2006, p. 472), ou seja, é necessário que, dentro de nossa experiência, encontremos os componentes que nos farão aproximarmonos da vivência do outro, sem o que esta se nos mostrará sempre como estranha e incognoscível.

No caso dos estudos com a criança, isso nos leva à produção ou à recuperação de uma espontaneidade, que, uma vez ativa, permite-nos achegar-nos ao devir infantil

\begin{tabular}{|l|c|c|c|c|}
\hline Govista Dialectus & Ano 9 & n. 19 & Agosto-Dezembro 2020 & p. 13-24 \\
\hline
\end{tabular}


posto no mundo, levando-nos a não mais prendermo-nos a noções que, como bem aponta o filósofo, mantêm a análise fixada em um conjunto limitador de ideias pré-definidas.

Isso pode ser notado, por exemplo, na insistência por parte de pesquisadores em caracterizar a natureza infantil, o que, segundo Merleau-Ponty, é preciso que se evite com rigor:

\begin{abstract}
Devemos evitar toda e qualquer concepção rígida, simplesmente estatística, dos estágios da infância (por exemplo, falar da natureza da criança de tal idade), toda e qualquer concepção rígida da psicologia dos sexos; nos testes, não devemos considerar os resultados em dado momento como verdadeiros absolutamente: eles indicam um estado momentâneo da dinâmica pessoal e interpessoal (2006, p. 473).
\end{abstract}

De igual maneira, em estreita ligação com o compromisso do pesquisador fenomenológico em ir a fundo na exploração do universo da criança a partir de si, é preciso estar atento para a maneira como deve ser conduzido o processo de compreensão da representação do mundo feita pela criança:

Quando se pedem à criança enunciados sobre questões gerais pede-se que ela totalize, condense sua experiência em certo número de fórmulas. A própria ideia de representação do mundo supõe a possibilidade de encontrar na criança uma tese sobre o mundo. [...] Assim, quando interroga a criança sobre o lugar do pensamento, esta lhe responde que ele está na garganta, na língua, na cabeça ou na respiração. Caberá concluir daí que para a criança o pensamento é algo material, no sentido adulto da palavra, que ele ainda não fez a distinção entre pensamento e corpo? Mas as palavras respiração, voz, garganta têm significado infantil. A criança as entende como voz e respiração vivenciadas por ela a partir do interior; não significa obrigatoriamente que ela confunde pensamento com objeto. Há na criança uma noção de corpo fenomênico indiviso entre pensamento e extensão. (MERLEÁU-PONTY, 2006, p. 476).

Outros pressupostos metodológicos merecem ser ainda considerados. A não submissão ao princípio estatístico, a possibilidade da ênfase em um ou num conjunto delimitado de casos: "a monografia, se feita em profundidade, tem tanto valor quanto um estudo superficial de numerosos casos, ou mais valor" (p. 479), são orientações que complementam o cenário de apreensão do mundo pelo olhar do fenomenólogo, e que o colocam numa condição bastante diversa daquele que, munido de conceitos mais ou menos cartesianos, dedica-se tão somente à descrição do universo dos sujeitos individuais e a sua forma de olhar para o exterior, sem ter a pretensão maior de construir uma

\begin{tabular}{|l|c|c|c|c|}
\hline Govista Dialectus & Ano 9 & n. 19 & Agosto - Dezembro 2020 & p. $13-24$ \\
\hline
\end{tabular}


totalidade capaz de compreender a raiz dos eventos que observa, verdadeiro objetivo da prática fenomenológica.

Resta ainda pensar na questão dos limites da abordagem da fenomenologia, em vista de sua recusa à historicidade. Nesse ponto, é significativo notar que a relevância dada por Merleau-Ponty ao termo devir aponta para a ideia de um pensamento fenomenológico não refratário às nuances do tempo. Além disso, a integração da fenomenologia a outras correntes epistemológicas tem se mostrado bastante fecunda, em especial na construção da chamada fenomenologia hermenêutica, a qual encontra, na obra de Paul Ricoeur (2008) um importante momento de sua realização, e que permite superar os impasses aqui discutidos e compondo, dessa maneira, uma epistemologia completa, capaz de lidar com os mais variáveis e multifacetados aspectos da experiência humana.

\section{Considerações finais}

A tarefa fenomenológica na educação está longe de ser encerrada. Tampouco está restrita a aspectos pontuais da vivência escolar. Onde quer que haja fenômenos pedagógicos relevantes, a fenomenologia pode atuar de forma efetiva e converter-se num importante amparo epistemológico para deslindar a natureza de sua manifestação.

Contudo, para que tal se efetive, é necessário romper com as cristalizações e reducionismos que foram aos poucos sendo consolidados dentro de sua prática metodológica na pesquisa educacional. Somente assim será possível realmente afirmar o significado fenomenológico dos eventos, como também promover acréscimos significativos não apenas para os objetos perscrutados, como também para o próprio fundamento epistemológico das investigações.

Trata-se de algo que ocorrerá somente mediante a leitura atenta e minuciosa dos textos, em especial aqueles que dizem respeito à origem do pensar fenomenológico, sem os quais a teoria não possui meios para desenvolver-se. Assim, cabe a cada pesquisador que se interessar pelo seu método, por seguir nos rumos dessa doutrina epistemológica, percorrer por tal caminho, para em seguida rumar de maneira firme e segura nos valiosos percursos da redução fenomenológica e do deslindamento das essências que determinam o fundo da prática educativa.

\begin{tabular}{|l|c|c|c|c|}
\hline Govista Dialectus & Ano 9 & n. 19 & Agosto-Dezembro 2020 & p. 13-24 \\
\hline
\end{tabular}




\section{Referências}

HEIDEGGER, Martin. Ser e tempo. Petrópolis, RJ: Vozes; Bragança Paulista, SP: Editora Universitária São Francisco, 2015.

HUSSERL, Edmund. A ideia da fenomenologia. Lisboa: Edições 70, 2005.

Ideias para uma fenomenologia pura e para uma fenomenologia fenomenológica: introdução geral à fenomenologia pura. Aparecida, SP: Ideias \& Letras, 2006.

Meditações Cartesianas. São Paulo: Madras, 2001.

MERLEAU-PONTY, Maurice. Fenomenologia da percepção. São Paulo: Martins Fontes, 1999.

Psicologia e pedagogia da criança: Curso da Sorbonne. São Paulo, Martins Fontes, 2006.

RICOEUR, Paul. Hermenêutica e ideologias. Rio de Janeiro: Vozes, 2008.

TRIVIÑOS, Augusto Nibaldo Silva. Introdução à pesquisa em ciências sociais: a pesquisa qualitativa em educação. São Paulo: Atlas, 1987.

\begin{tabular}{|l|l|l|l|l|}
\hline Q Rovista Dialectus & Ano 9 & n. 19 & Agosto - Dezembro 2020 & p. 13-24 \\
\hline
\end{tabular}

